\title{
Efficiency of Plant Breeding
}

\author{
Salvatore Ceccarelli $\star$
}

\begin{abstract}
Participatory plant breeding (PPB) has been practiced for several reasons, including sociological, humanitarian, and egalitarian. This paper aims to demonstrate that PPB should be practiced simply because it increases plant breeding efficiency, which is defined as (i) the ratio between the number of varieties adopted and the number of crosses made, (ii) the response to selection, and (iii) the benefit/cost ratio, not only as often done by public breeding programs, by the number of varieties released by public breeding programs. After reviewing the reasons for the lack of adoption of several of the varieties released, and the theoretical basis justifying the use of correlated response to measure selection gains, the issue of the benefit/cost ratio is discussed within the context of adoption rates. The assumption is that without adoption, no benefit will occur. Ways to increase the three measures of breeding efficiency are discussed in detail, and the conclusion is made that the three measures can be increased by combining decentralized selection with farmers' participation in a PPB program. The essential features of a PPB program are reviewed, including the experimental designs and statistical analysis used to increase the precision of onfarm trials. The findings show that PPB increases breeding efficiency, both in terms of response to selection measured over the time from the initial cross to adoption and in terms of the benefit/cost ratio as a consequence of a higher adoption rate. In a PPB program, adoption starts during the process of selection and precedes variety release. In a conventional plant breeding (CPB) program, the sequence is reversed. Other differences between a PPB and a CPB program include the increase of agrobiodiversity, which in a PPB program is higher because of the rapid spatiotemporal turnover of varieties, and because the seed of new varieties is readily available to farmers, thus contributing to food security. Because of its decentralized nature, PPB can accommodate organic farms and become easily adopted by both national and international public breeding programs as one way of adapting crops to climate changes.
\end{abstract}

Consultant, International Center for Agricultural Research in Dry Areas (ICARDA), P.O. Box 114/5055, Beirut, Lebanon. Received 27 Feb. 2014. `Corresponding author (s.ceccarelli@cgiar.org; ceccarelli. salvatore83@gmail.com).

Abbreviations: BLUPs, best linear unbiased predictors; CPB, conventional plant breeding; CR, correlated response; GEI, genotype $\times$ environment interaction; GL, genotype $\times$ location interaction; GY, genotype $\times$ years interaction; $h^{2}$, heritability; ICARDA, International Center for Agricultural Research in Dry Areas; IRR, internal rate of return; MET, multienvironment trial; PPB, participatory plant breeding; QTL, quantitative trait loci; TPE, target population of environments.

$\mathrm{P}$ LANT BREEDING has been a key science in improving crop production, with an estimated contribution to productivity increases of around 50\% (Fehr, 1984). Over the past decades, it has remained a vibrant science, with continued success in developing and deploying new cultivars on a worldwide basis (Gepts and Hancock, 2006).

A plant breeding program is a cyclical process aimed at the development of new cultivars, whereby each cycle consists of three major phases (Allard, 1960; Schnell, 1982; Gepts, 2002; Ceccarelli, 2009): (i) generating genetic variability: this includes making crosses, inducing mutation, introducing exotic germplasm, and using genetic engineering techniques; (ii) selection and testing to identify superior recombinants: in self-pollinated, cross-pollinated, and vegetatively propagated crops, which is done with different methods such as marker-assisted selection, introgression of quantitative trait loci (QTL), or use of high-throughput phenotyping platforms, and which terminates with the identification of potential cultivars; (iii) release, distribution, and adoption of new cultivars:

Published in Crop Sci. 55:87-97 (2015).

doi: 10.2135/cropsci2014.02.0158

Freely available online through the author-supported open-access option.

(C) Crop Science Society of America | 5585 Guilford Rd., Madison, WI 53711 USA

All rights reserved. No part of this periodical may be reproduced or transmitted in any form or by any means, electronic or mechanical, including photocopying, recording, or any information storage and retrieval system, without permission in writing from the publisher. Permission for printing and for reprinting the material contained herein has been obtained by the publisher. 
the yield testing in multienvironment trials (METs) is either the last step of the second phase or the first step of the third. Two additional steps are often included as essential components of a breeding program, namely, setting the objectives and evaluating the program in terms of reaching those objectives. These two steps come before and after, respectively, the three phases mentioned earlier.

In this paper, we consider three measures of plant breeding efficiency: (i) the ratio between the number of varieties adopted and the number of crosses made at the beginning of a given breeding cycle (Witcombe et al., 2013); (ii) the response to selection for the trait or traits selected (usually expressed as percentage of the value of the same traits in a reference variety); and (iii) the benefit/cost ratio of different plant breeding methodologies. Plant breeding efficiency is different from selection efficiency, although the two are sometimes used synonymously (Wallace et al., 1993).

The objectives of this paper are to (i) discuss the validity of the most commonly used methods of measuring the efficiency of a breeding program, (ii) suggest alternative ways of measuring the efficiency of a plant breeding program, and (iii) show how decentralization and the inclusion of farmers' participation increase the efficiency of a plant breeding program using the three measures listed above.

\section{Measures of Plant Breeding Efficiency}

In most public breeding programs, including those of the CGIAR (formerly the Consultative Group on International Agricultural Research), the most common way of measuring the efficiency of a plant breeding program is by the number of varieties released, as indicated by the annual reports of National and International Research Centers. The efficiency of a plant breeding program is less commonly measured in terms of selection gain (or response to selection) obtained in a particular cycle (consisting of the five phases described above) or as the average of a number of cycles, and as benefit/cost ratio, which has been used mostly by economists in impact studies (Maredia and Raitzer, 2010).

\section{Variety Release}

The number of varieties released is, as mentioned above, the most common way of measuring the efficiency of plant breeding by public institutions, both national and international, presumably because it is easy to measure. The annual reports of these institutes typically publish updated tables with the number of varieties released for the various crops. See, for example, the Annual Reports of the CGIAR at www.cgiar.org. Those tables do not mention whether the varieties have been adopted by farmers. In some cases, the tables note the estimated net benefit, but without an indication of the levels of adoption assumed to obtain those estimates, although exceptions exist (ICRISAT, 2012). Whenever used, adoption is defined as the percentage of the area of the crop grown with a given variety at any point in time, or by the percentage of farmers growing the variety. In measuring adoption, the importance of the length of time a new variety is cultivated remains unclear given that farmers often adopt new varieties for a short time and/or on a limited area before returning to the previously adopted variety or to the landrace.

The number of varieties released is a gross overestimate of the efficiency of a breeding program. In fact, if we accept that plant breeding generates benefits when the varieties it produces are used by the farmers (Morris and Heisey, 2003; Maredia and Raitzer, 2010), a released variety never adopted by farmers does not generate benefit. One can argue that such a variety can still be of benefit to the breeders when used as a parent, but this benefit would only be reflected in the adoption of varieties derived from that parent.

Variety release is merely an administrative recognition often based on poorly designed and unrepresentative trials (see below), and in several countries is needed to legally commercialize the seed. However, in many developing countries, the "legal" seed, particularly in crops grown in marginal environments, only represents a small percentage of the seed that is actually planted, while the majority of seed is produced by the informal sector, defined as the total of farmers' seed production, selection, and seed exchange activities (Bishaw and Turner, 2008). This makes variety release an even less credible measure of plant breeding efficiency. The issues of seed availability and variety adoption are intimately connected, as lack of adoption is often attributable to the unavailability of seed from improved varieties.

It is widespread and common knowledge that, particularly in developing countries, a mismatch exists between the varieties released and those grown by farmers, in the sense that there are varieties released but not adopted, and varieties grown by farmers but not released. This mismatch varies with the crop, usually being higher for crops grown in marginal environments (Aw-Hassan et al., 2008). Examples of this mismatch are given in Table 1, with examples of different adoption in different agroecologies. In the last four rows of the table, numerical examples of the difference between varieties released versus adopted for different crops and countries are presented. A similar situation has been described for maize (Zea mays L.) in the Guangxi Province of China (Li et al., 2012) and for sorghum [Sorghum bicolor (L.) Moench] in Nigeria (Flower, 1996).

The reasons for lack of adoption or for limited adoption are several and have been discussed by Weltzien and Witcombe (1989), Ceccarelli et al. (1991), Saade et al. (1993), Brush (1995), Legg and Thresh (2000), Sall et al. (2000), Hossain et al. (2012), Li et al. (2012), Reguieg et al. (2013), and Yahiaoui et al. (2014).

Even if the yield of improved varieties is greater than or similar to that of the local variety, farmers may not adopt them. Yield is not the only criterion for adoption 
Table 1. Adoption of varieties (percentage of area) as affected by the crops (Jansen et al., 1990) and the region (Kelley et al., 1996), and as a ratio over the number of varieties released.

\begin{tabular}{|c|c|c|c|c|c|}
\hline \multirow[b]{2}{*}{ Crop $^{\dagger}$} & \multirow[b]{2}{*}{ Country } & \multirow[b]{2}{*}{ Region } & \multicolumn{2}{|c|}{ Adoption } & \multirow[b]{2}{*}{$\begin{array}{l}\text { Quoted } \\
\text { from }\end{array}$} \\
\hline & & & $\%$ area & $\begin{array}{l}\text { ratio adopted/ } \\
\text { released }\end{array}$ & \\
\hline Wheat & India & & $83 \%$ & & Jansen et al., 1990 \\
\hline Rice & India & & $60 \%$ & & Jansen et al., 1990 \\
\hline Sorghum & India & & $32 \%$ & & Jansen et al., 1990 \\
\hline Pearl millet & India & & $49 \%$ & & Jansen et al., 1990 \\
\hline Maize & India & & $36 \%$ & & Jansen et al., 1990 \\
\hline Pearl millet & India & Gujarat, Tamil Nadu, and Andhra Pradesh & $90 \%$ & & Kelley et al., 1996 \\
\hline Pearl millet & India & $\begin{array}{c}\text { dry areas of Haryana, Karnataka, and } \\
\text { Maharashtra }{ }^{\ddagger}\end{array}$ & $30 \%$ & & Kelley et al., 1996 \\
\hline Rice & India & & & $2 / 525$ & Witcombe et al., 1996 \\
\hline Barley & Algeria & & & $2 / 16$ & Reguieg et al., 2013 \\
\hline Barley & Syria & & $10 \%$ & $2 / 8$ & Ceccarelli et al., 2011 \\
\hline Rice & Nepal & & $\begin{array}{l}10-11 \% \text { of } \\
\text { household }\end{array}$ & & Sthapit et al., 1996 \\
\hline
\end{tabular}

† Wheat (Triticum aestivum L.), Rice (Oryza sativa L.), Sorghum [Sorghum bicolor (L.) Moench], Pearl millet [Pennisetum glaucum (L.) R. Br.], Maize (Zea mays L.), Barley (Hordeum vulgare L.).

‡ Represents $40 \%$ of the pearl millet area.

(Sall et al., 2000; Jalleta, 2004), as shown also by AwHassan et al. (2008), who listed 15 different criteria used by farmers to decide whether to adopt a variety. Lack of adoption of a variety may adversely affect the adoption of other agricultural technologies, as farmers have been known to adopt technologies in a stepwise fashion (Byerlee and de Polanco, 1986).

The literature on the issue of variety adoption is very rich, suggesting that in general, it is very difficult during the breeding program to predict whether or not the varieties will be adopted. This is in part because in a conventional system, 5 to 6 yr typically pass after official release before appreciable adoption commences (Morris et al., 1992; Witcombe et al., 1998), and during this time, farmers' priorities, agronomic conditions (e.g., availability of irrigation or fertilizer price), policy measures (e.g., introduction or removal of subsidies), and market demands may change, making the breeding objectives set at the beginning of the breeding program obsolete.

Ex post impact studies by socioeconomists consistently show that farmers' perception of a new technology significantly affects its adoption, and therefore, the participation of farmers in technology development seems to be the most logical strategy to increase the probability of adoption, and hence, the efficiency of the breeding program (Adesina and Baidu-Forson, 1995; Sall et al., 2000).

The nonadoption of numerous released varieties is likely to be due to the process of variety release. This process differs from country to country. The two most common systems are first, independent trials that are conducted at the end of the breeding program with results submitted to an ad hoc committee that decides if the variety can be accepted for release. If accepted, the production of certified seed starts, although there could be some slight differences from country to country. In the second system, the breeder prepares a report on the performance of the lines in his or her own breeding trials and the report is submitted to the ad hoc committee, which decides if the variety can be accepted for release. The first system adds an additional 3 to $4 \mathrm{yr}$ to the time needed to obtain a new variety with conventional breeding, while the second is about 2 to 3 yr shorter than the first.

Tripp et al. (1997) identified four categories of problems associated with the information needed to submit a variety for release, namely, efficiency, standards, participation, and transparency (Table 2). Some of the problems listed in Table 2 have been mentioned earlier by Wien (1987) and Thomas (1987) and, more recently, with specific reference to organic agriculture, by Belicka and Bleidere (2005).

An additional problem observed in variety testing, and not only in developing countries, is the use of obsolete experimental designs and statistical analysis, with no attempts to capture spatial variability and correlation between the plot errors (Singh et al., 2003; Ceccarelli, 2012) or of increasing the number of locations by the use of partial replication (Cullis et al., 2006) combined with optimized randomization (www.austatgen.org/software; accessed 14 Sept. 2014). One example of the failure of official variety testing is given by the rejection in Syria of three barley (Hordeum vulgare L.) varieties, which were later adopted by dryland farmers on areas of between 10,000 and 50,000 ha (ICARDA, 2007; Ceccarelli et al., 2013b). Obviously not all variety-testing systems suffer from all the drawbacks listed in Table 2, but only a few of them are sufficient to affect the results in such a way that the variety released has a low probability of adoption. 
Table 2. Problems associated with the way trials for variety release are organized and conducted. Modified from Tripp et al. (1997).

\begin{tabular}{lc}
\hline \multicolumn{1}{c}{ Problems } & Examples \\
\hline Efficiency & $\begin{array}{c}\text { Low frequency of variety replacement } \\
\text { Uneven resource allocation to different trial stages } \\
\text { Prolonged variety testing } \\
\text { Inappropriate site selection } \\
\text { Inappropriate zoning }\end{array}$ \\
\hline Standards & $\begin{array}{c}\text { Unrepresentative trials management } \\
\text { Trials' analysis biased against poor environments } \\
\text { Lack of attention to farmer-relevant variety traits }\end{array}$ \\
\hline Participation & Lack of participation by related organizations \\
Lransparency & Lack of coordination between national and regional \\
testing systems and lack of accountability and linkages
\end{tabular}

\section{Selection Gains (or Response to Selection)}

The selection gain (or response to selection) is defined as $R=S h^{2}$, where $S$ is the selection differential (the difference between the mean of the selected individuals and the mean of the whole population) and $h^{2}$ is the heritability of the target traits (Falconer, 1981). The selection differential is determined by the intensity of selection (i), which depends on the percentage of individuals selected and is equal to $S / \sigma_{p}$, where $\sigma_{p}$ is the square root of the phenotypic variance. Therefore, the response to selection can also be expressed as $R=i h^{2} \sigma_{\mathrm{p}}$.

Breeding methods may differ in the number of seasons required per cycle. Eberhart (1970) introduced the number of seasons per cycle $(\gamma)$ into the formula, so that it becomes, in a simplified form,

$$
R=\left(i h^{2} \sigma_{\mathrm{p}}\right) / y,
$$

where the heritability $h^{2}$ is equal to

$$
h^{2}=\sigma_{\mathrm{g}}^{2} / \sigma_{\mathrm{p}}^{2}=\sigma_{\mathrm{g}}{ }^{2} / \sqrt{ } \sigma_{\mathrm{e}}^{2} /(r e)+\sigma_{\mathrm{ge}}{ }^{2} / r+\sigma_{\mathrm{g}}^{2},
$$

where $\sigma_{\mathrm{p}}^{2}, \sigma_{\mathrm{e}}^{2}, \sigma_{\mathrm{ge}}^{2}$, and $\sigma_{\mathrm{g}}^{2}$ are the phenotypic, environmental, genotypic $\times$ environment interaction (GEI), and genotypic variances, respectively, and $r$ and $e$ are the number of replications and the number of environments (locations, years, or location-years combinations), respectively.

Formula [1] assumes that the selection environment and the target environment are the same. However, the most common case is that the selection environment (one or more research stations) is different from the target environment (the farmers' fields), with some Australian breeding programs being the best-known exception. Therefore, the formula of the direct response to selection (1) is, in most cases, irrelevant because the research station cannot possibly be the target environment. The selection gains should then be calculated as the correlated response to selection (CR) in the target environment, which is equal to

$$
\mathrm{CR}_{\mathrm{t}}=R_{\mathrm{s}} h_{\mathrm{t}}^{2} / h_{\mathrm{s}}^{2} \mathrm{r}_{\mathrm{g}} \text { or } i h_{\mathrm{t}} h_{\mathrm{s}} r_{\mathrm{g}} \sigma_{\mathrm{pt}}
$$

(Falconer, 1981; Annicchiarico, 2002), where $\mathrm{R}_{\mathrm{s}}$ is the response to selection in the selection environment, $\mathrm{h}_{\mathrm{t}}^{2}$ is the heritability in the target environment, $\mathrm{h}_{\mathrm{s}}{ }^{2}$ is the heritability in the selection environment, $\mathrm{r}_{\mathrm{g}}$ is the genetic correlation coefficient between the measures of the trait object of selection in the two environments, and $\sigma_{\mathrm{pt}}$ is the phenotypic standard deviation of the trait in the target environment.

In the case of a target population of environments (TPE), which are several geographical areas the breeding program aims to serve, $\mathrm{CR}_{\mathrm{t}}$ can be calculated separately for each target environment or across the TPE, if the same variety is selected for the entire TPE. Eventually, CR $\mathrm{t}_{\mathrm{t}}$ should also be expressed in terms of cycle time, as in the case of $R$.

An issue debated for a long time by plant breeders, particularly in relation to breeding for stress environments, is whether it is more efficient to select directly in the target environment $\left(R_{\mathrm{t}}\right)$, or to select in the research station $\left(R_{\mathrm{s}}\right)$, which is considered as an ideal selection environment because of higher heritability (Allen et al., 1978), and rely on the correlated response to selection in the target environment (CR ) (Calhoun et al., 1994; Ceccarelli, 1994; Cooper et al., 1997; Atlin et al., 2001; Annicchiarico et al., 2005; Annicchiarico, 2007). The relationship between $\mathrm{CR}_{\mathrm{t}}$ and $R_{\mathrm{t}}$, assuming that $\gamma$ is the same, is given by

$$
\mathrm{CR}_{\mathrm{t}} / R_{\mathrm{t}}=r_{\mathrm{g}}\left(h_{\mathrm{s}} / h_{\mathrm{t}}\right),
$$

which will also apply in the case of selection for one trait to obtain a gain from selection in another trait (Falconer, 1981).

When $h_{\mathrm{t}}=h_{\mathrm{s}}$, the maximum value of $\mathrm{CR}_{\mathrm{t}} / R_{\mathrm{t}}$ is 1 , when $r_{\mathrm{g}}=1$. When heritabilities are the same, direct selection will always be more effective $\left(R_{\mathrm{t}}>\mathrm{CR}_{\mathrm{t}}\right)$ because the genetic correlation coefficient will always be less than 1 . With low genetic correlations $(0.1-0.2)$, which are often found between high-yielding breeding nurseries and lowyielding target environments (Atlin et al., 2001), $h_{\mathrm{s}}$ must be at least 5 to 10 times higher than $h_{t}$ for $\mathrm{CR}_{t}$ to be greater than $\mathrm{R}_{\mathrm{t}}$. A literature review showed that the ratio between $h_{\mathrm{s}}$ and $h_{\mathrm{t}}$ does indicate that generally $R_{\mathrm{t}}>\mathrm{CR}_{\mathrm{t}}$ (Ceccarelli, 1996). Heritability alone is not sufficient to determine the optimum selection environment because when $r_{\mathrm{g}}$, is negative, as in the case of GEIs of crossover type, the magnitudes of $h_{\mathrm{s}}$ and $h_{\mathrm{t}}$ become irrelevant.

\section{Costs and Benefits of a Breeding Program}

The ratio between the benefits generated by a new variety and the cost associated with developing that variety could be an additional way of measuring the efficiency of a plant breeding program, although it has been mostly 


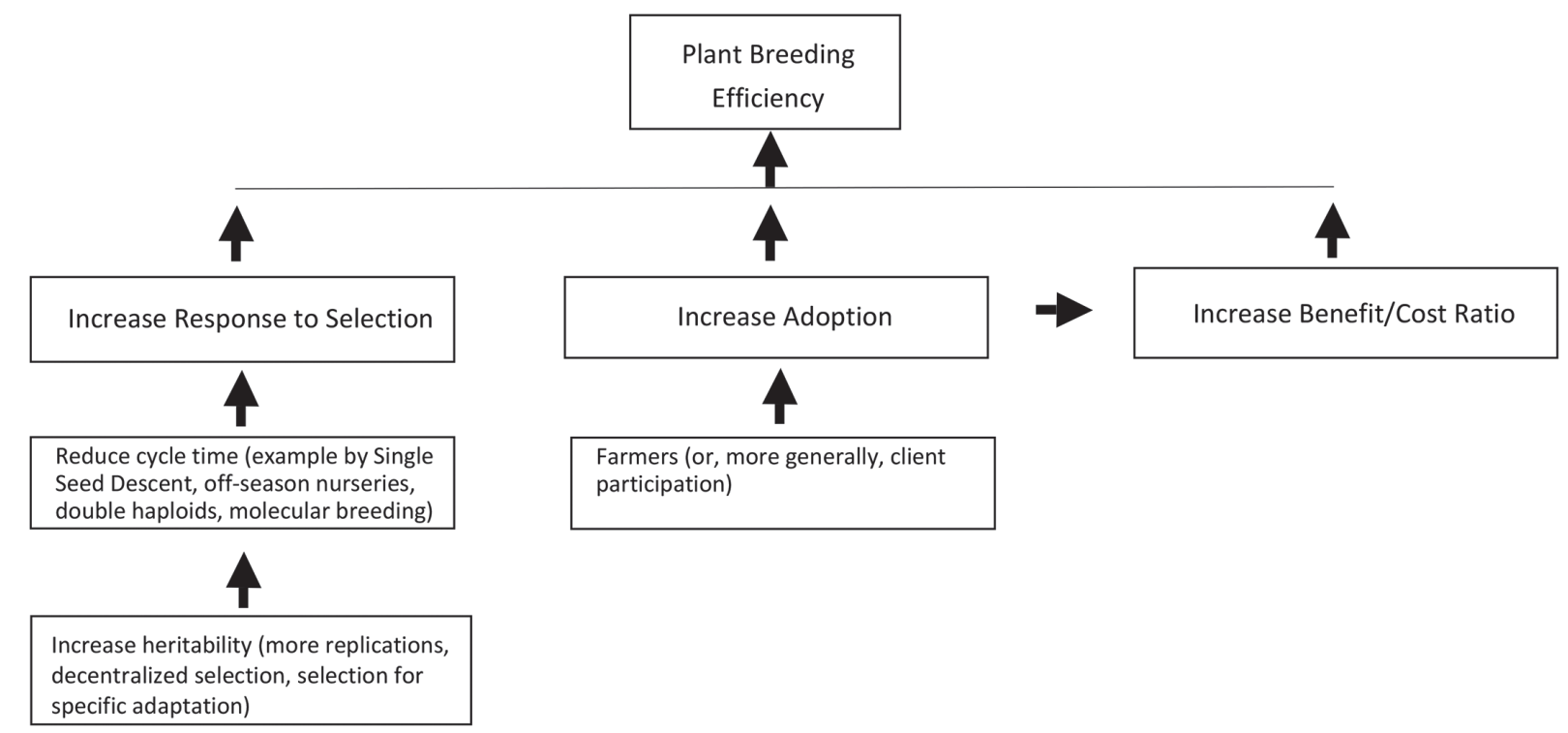

Figure 1. Plant breeding efficiency can be increased by increasing response to selection, adoption, and benefit/cost ratio.

used in impact studies (Maredia and Raitzer, 2010). Several impact assessment studies consistently show that the economic benefits generated by plant breeding are large, positive, and widely distributed (Morris and Heisey, 2003), even if concerns have been expressed about the methodology used. Many of these studies assume, implicitly or explicitly, that a benefit could not occur unless the varieties are adopted (Maredia and Raitzer, 2010), thus supporting the argument that adoption, rather than release, should be used as a measure of efficiency (Sall et al., 2000). However, the benefits could be of a different nature to different people (Simmonds and Smartt, 1999) and come at varying costs depending on the breeding methodology, the crop, the country, and the social context, thus bringing economic criteria into a breeding program.

The reasons why variety release and variety adoption are the measures of plant breeding efficiency predominantly used in public and private breeding, respectively, are probably associated with the issue of who benefits from the production of new varieties (Simmonds and Smartt, 1999). Obviously, the private breeders must make a profit, which is only possible through seed sale. Profit increases if farmers have to purchase the seed every year, which may influence the production of certain varieties versus others (e.g., hybrids instead of open-pollinated varieties), but in any case, adoption is a key factor. To a public breeder, the release of a variety could be the ultimate goal. In several countries, this becomes part of the breeders' scientific recognition, particularly if the lack of adoption can be attributed, as mentioned earlier, to the lack of seed. Seed production and distribution are not considered the breeders' direct responsibility. In the case of nonadoption, the social benefits one would expect from a public breeding program will not be fulfilled (Simmonds and Smartt, 1999).
The cost-benefit analysis has been criticized as suffering from several drawbacks (Simmonds and Smartt, 1999), but it does not have alternatives and is the only way to consider the output of a breeding program in a social context. Two examples of a cost-benefit analysis of alternative ways of implementing a breeding program are given later in the paper.

\section{Increasing Plant Breeding Efficiency}

On the basis of the definitions given earlier, plant breeding efficiency can be increased by increasing either the response to selection, the adoption of varieties, or the benefit/cost ratio (Fig. 1). Using the formula for CR, response to selection in the target environment can be increased by reducing the cycle time, $y$, which breeders call the time from cross to cross, although it is perhaps better defined as the time from cross to variety adoption. This can be achieved, for example, by using off-season nurseries at lower latitudes or in the opposite hemisphere, using two cropping seasons in a situation of bimodal rain distribution, single-seed descent in self-pollinated crops (Goulden, 1939), the double-haploid technique, or via biotechnology tools such as the introgression of QTLs (Ribaut and Hoisington, 1998). However, the adoption of biotechnological tools is still limited, particularly for complex traits like yield under environmental stress (Ribaut et al., 2010), for which an increase in selection efficiency is most needed. An example of reduction of the breeding cycle time is the development of rice varieties tolerant to salinity, when the savings was at least 2 to $3 \mathrm{yr}$ (Alpuerto et al., 2009).

Other ways of increasing response to selection (Fig. 1) are to increase $h^{2}$ by increasing the number of replications in the selection environment and to increase the magnitude of $r_{g}$ by conducting decentralized selection. Increasing the number of replications is expensive and is contrary to the current trend of reducing replications and 
increasing the number of locations in METs. Decentralized selection makes the selection environment and the target environment as similar as possible (Atlin et al., 2001), so that a response to selection that approximates $R$ rather than CR will be measured. This will also result in a reduction in $\sigma_{\text {ge }}{ }^{2}$, namely the variance component due to GEI, commonly considered as one of the major factors reducing the efficiency of plant breeding programs. This is achieved by subdividing GEI into its two components, namely genotype $\times$ locations (GL) and genotype $\times$ years (GY), by assessing the repeatability of GL and eventually subdividing the TPE in such a way that the GEI within each subgroup is lower than that across the entire TPE (Windhausen et al., 2012). The increase in selection gain, by selecting for specific adaptation within subgroups of target locations as opposed to selecting for wide adaption across groups, was demonstrated experimentally by Annicchiarico et al. (2005) and Annicchiarico (2007).

Decentralized selection, defined as selection in the early stages of a breeding program conducted in the target environments (Falconer, 1981; Simmonds, 1991), is a key factor in increasing response to selection. The research stations cannot fully capture the farmers' agronomic management practices, including soil preparation and tillage, use of chemical input, irrigation, and crop rotations.

Although the strategies to increase breeding efficiency by increasing the response to selection may appear obvious, the reality of most public plant breeding programs, both at national and international institutions, is that several cycles of selection are conducted on research stations, and only the final testing of relatively few lines is conducted in farmers' fields. The resistance to decentralization, both by national and international plant breeders, is often justified by the superior precision of the breeding trials conducted on-station. While often true, this may be irrelevant. Work in Australia showed that genetic correlations between the yield of breeding lines on-station and yield under on-farm conditions were low in comparison to the genetic correlations between different on-farm experiments (Pederson and Rathjen, 1981; Cooper et al., 1997). Although lower experimental errors and higher heritability are obtained on research stations, the results have limited relevance to genotype performance in the on-farm target population of environments (Bänziger and Cooper, 2001). Therefore, the issue is how to make the breeding trials conducted onfarm more precise. This brings up the second reason often used to justify centralized selection, namely the limited amount of seed generally available in the early stages of a breeding program. The prevalent practice is to use all the seed available to do an unnecessarily large number of replications on-station, with no seed left to plant trials outside the station. Today, new classes of experimental designs, such as the partially replicated design in rows and columns, the use of optimized randomization (www. austatgen.org/software, accessed 14 Sept. 2014) and of spatial analysis (Ceccarelli, 2012), makes it possible to sacrifice replications in favor of locations, thus allowing an early evaluation of the breeding material in METs with a sufficiently high degree of precision. In the early stages of a breeding program, the benefits from replications are less clear, as the main focus is on ranking genotypes rather than predicting their yields (Kempton and Gleeson, 1997).

The solutions discussed above, while capable of increasing response to selection, do not necessarily increase variety adoption, which is critical to increasing breeding efficiency (Sall et al., 2000) and result in an increased benefit/cost ratio if not associated with a disproportionate cost increase (Fig. 1). Many programs found that one effective way to increase the efficiency of plant breeding is to involve farmers, or more generally, the clients of the products of a breeding program, in the development of new varieties, rather than only in the final stage of testing (Bellon, 2006). This can be done by combining decentralization and farmer participation in what is known as participatory plant breeding (PPB; Ceccarelli et al., 2009).

\section{Increasing Breeding Efficiency through Decentralized Participatory Plant Breeding}

This section will show how PPB increases the efficiency of plant breeding by increasing the response to selection, variety adoption, and benefit/cost ratio. Given the five phases of a plant breeding program as described earlier, a PPB program differs from a conventional plant breeding (CPB) program as follows:

1. The objectives are established in communication with the farmers (Weltzien and Christinck, 2009), who often express their preferences for the type of genetic material to use in the program (e.g., landraces vs. modern varieties, populations vs. fixed lines) and for specific traits (e.g., seed color, plant height, fodder quality).

2. The breeding material is tested in farmers' fields at a much earlier stage than in a CPB program, ideally at the beginning of the third of the five phases.

3. Farmers are involved in all major decisions and particularly in deciding which material to carry further and which material to discard at the end of each cropping season. They also often suggest methodological innovations in the way selection is conducted or the trials are planted. Details of who participates and how are given in Ceccarelli et al. (2009) and Ceccarelli et al. (2013a).

4. Locations, chosen to sample as extensively as possible the target populations of environments and users, are treated as independent units of selection, that is, selection is done within each location regardless of how the best breeding lines in that location perform in other locations. Selection is fully decentralized and is for specific adaptation. 
5. The agronomic management of the trials is established with the farmers' consent, and different agronomic options, including organic farming, can be incorporated into the breeding trials.

6 . The objectives of the program are continuously monitored with the participating farmers.

Details, such as when to transfer the breeding material from research station to farmers' fields and the type of genetic material, vary with the crop, with farmers' preferences, and with the objectives of the program (Ceccarelli et al., 2009). For example, in those cases in which resistance to a pest is essential, the screening for that pest can be done on-station using molecular markers when available. Similarly, screening for the appropriate phenology, a key adaptation and high heritability trait can conveniently be done on-station. Traits important for marketing the crop can also be conveniently screened on-station, when not affected by GEI. The same can be done for other high heritability traits. This has the advantage of reducing the amount of breeding material to be tested in farmers' fields.

In the model we have developed for self-pollinated crops (Fig. 8.8 in Ceccarelli et al., 2013a), which is fully applicable to vegetatively propagated crops, the breeding material undergoes four cycles of selection in each location, in as many cropping seasons. Many agronomic and phenological data are recorded on a plot basis. Selection is done in two stages. First, selection is done by the farmers by visually scoring all the plots shortly before harvesting, while scientists measure several agronomic traits. Second, selection is done jointly by breeders and farmers on the basis of the adjusted means (BLUPs, or best linear unbiased predictors) generated by spatial analysis of all data recorded in the trial. The material selected at the end of the first year, usually 10 to $15 \%$ of the total, is tested for a second year following the same procedures. The material selected again at the end of the second year is tested for a third year, at the end of which usually 1 to 3 entries are left for the fourth and final year of testing in each location. At this point, the farmers name the entries they consider the best over the 4 -yr period and start seed multiplication. This is followed by seed sale outside the group of farmers who participated regularly in the selection process. The participating farmers have free access to the seed. This is considered as the initial adoption of the variety. The named entries are used by the breeders as parental material for crosses that will generate the breeding material for further cycles of decentralized participatory selection.

The principles of the method are applicable to crosspollinated crops as well, with technical modifications that depend on the type of variety (e.g., hybrid, openpollinated variety, synthetic) that is being produced. In the first-year trials, partially replicated row and column designs (Cullis et al., 2006) combined with optimized randomization are used, while in the second-, third-, and fourth-year trials, a randomized complete block design, with two replications in rows and columns with optimized randomization, is used. In all cases, the data are submitted to a spatial analysis (Singh et al., 2003), which generates the BLUPs to be used in joint meetings with farmers for selection as described earlier.

Eventually, while in each village one farmer grows the first-year trial, the second-, third-, and the fourth-year trials are usually grown by between three to five farmers (one farmer also grows the first-year trial) within the same village. This facilitates exposure of the breeding material, at an early stage of the breeding program, to several soil types and agronomic treatments because farmers, even within the same village, may use different amounts and types of input. In a CPB program, this takes place only at a much later stage.

The data generated during the $4 \mathrm{yr}$ of testing are equivalent to a MET data set; therefore, they can be used to submit the entries named by the farmers to the variety release committee for formal release with the designated area(s) for which they are recommended.

One of the main differences between a PPB program, as described above, and a CPB program is the temporal relationships between release and adoption. In a CPB program, a variety is first released and then adopted. In a PPB program, a variety is released after its adoption has already begun, and by the time the variety is released, it could be already grown on a few thousand hectares.

The model described above had been initially implemented in Syria with barley in 1996-1997 and gradually extended to Morocco, Tunisia, Jordan, Egypt, Algeria, Yemen, Eritrea, Ethiopia, and Iran with crops like barley, bread (Triticum aestivum L.) and durum wheat (Triticum turgidum L. var. durum), lentil (Lens culinaris Medikus subsp. culinaris), faba bean (Vicia faba L.), and chickpea (Cicer arietinum L.) (Ceccarelli and Grando, 2012). Recently similar programs have been started in Kenya with sorghum and in Uganda with cowpea (Vigna unguiculata L. Wasp). The PPB programs in other countries and crops are described by Cleveland and Soleri (2002).

Another important difference between a PPB program and a CPB program is the impact on agrobiodiversity (Gepts, 2006) and adaptation to climate changes. In a PPB program, because of the selection strategy described under (4) above, both the number of varieties produced and their turnover are higher than in a CPB program, thus increasing both spatial and temporal agrobiodiversity (Ceccarelli et al., 2013a).

Two examples of the contribution of PPB to agrobiodiversity, as compared with CPB, are offered by Syria and Algeria. In Syria, by 2011, 93 new barley varieties were named, adopted, and grown by farmers on areas between a few thousand hectares and 50,000 ha. In contrast, the General Commission for Scientific and Agricultural 
Research (GCSAR) released eight barley varieties between 1978 and 2004 (www.gcsar.gov.sy/gcsarEN/spip. php? article119, accessed 14 Sept. 2014), of which only two were actually grown by the farmers on less than $10 \%$ of the area. In Western Algeria, at the end of a PPB cycle of $5 \mathrm{yr}$, eight barley varieties were selected by farmers and multiplied for further distribution (Reguieg et al., 2013). Since its establishment in 1966, the Institut National de la Recherche Agronomique d'Algerie (INRAA) released 16 barley varieties, including the purification of two landraces. These two landraces are the only two of the 16 varieties that have actually been adopted (Reguieg et al., 2013). Similar results have been obtained with bread and durum wheat in Eastern Algeria, with five bread wheat and three durum wheat varieties already planted in farmers' fields (A. Benbelkacem, personal communication, 2014). Other examples of a farmer participatory crop improvement program contributing to agrobiodiversity are given by Witcombe et al. (1996).

In addition to the contribution to agrobiodiversity, other advantages of PPB are the following:

1. The speed with which new varieties became available to farmers and, therefore, the contribution to achieving food security (Jones et al., 2014).

2. The ability to address gender-based crops vis-à-vis the increasing feminization of agricultural labor in developing countries (Ceccarelli et al., 2013a).

3. The possibility of improving underutilized crops.

4. The possibility of selecting varieties for organic agriculture (Wolfe et al., 2008).

A PPB program organized as described above increases plant breeding efficiency by:

1. Increasing the magnitude of $r_{\mathrm{g}}$ by transferring the selection from the research station to one or more farmers' fields chosen as the most representative of the TPE in terms of climate, soil type, agronomic practices, and socioeconomic context.

2. Increasing $h^{2}$ by subdividing the TPE into many small subgroups, hence, reducing the $\sigma_{\mathrm{gl}}{ }^{2}$ component of $\sigma_{\mathrm{ge}}{ }^{2}$. Note that the subdivision of TPE into small groups can be optimized by analyzing the discriminating ability of the test environments and their representativeness using GGE Biplot software (Yan et al., 2007).

3. Reducing the breeding cycle $y$ (as time from cross to release) by eliminating the on-farm testing needed in many systems for the release of varieties, as almost the entire program is on-farm. Even more importantly, it reduces the time from cross to adoption because adoption precedes release.
4. Increasing the ratio of varieties adopted to crosses made, because the preferences of the farmers are part of the selection process, and the breeding material that reaches the end of the selection process has been chosen by the farmers under their growing conditions, thus reducing or eliminating the negative effects of GEI.

5. Increasing the benefit/cost ratio (see below) as a direct consequence of the increased ratio of variety adopted/crosses made.

\section{Two Examples of a Cost-Benefit Analysis of Participatory and Conventional Plant Breeding Programs}

We compared the cost of a CPB program with that of a PPB program using the example of Syria, where the two breeding program types coexisted for a sufficient number of years and the necessary data were available. That comparison indicated that in the case of the International Center for Agricultural Research in Dry Areas (ICARDA) barley breeding program, no relevant cost differences were incurred between the PPB and CPB programs (Mangione et al., 2006), largely because the PPB program reaches the same level of development of the breeding material $3 \mathrm{yr}$ earlier than the CPB program. Depending on the type of $\mathrm{CPB}$ program and on the combination of the number of sites and number of farmers per site in the PPB program, the aggregated costs of the PPB program were lower than those of the CPB program by between 5 and $28 \%$.

The study described above did not consider the benefit/ cost ratio associated with different ways of organizing a breeding program. This type of analysis was performed in Mexico (Smale et al., 2003) and in Syria (Ceccarelli et al., 2012).

In the Mexican case, farmers as a group earned a high benefit/cost ratio from participating, although the returns were low from the perspective of private investors. The project also generated social benefits, but these would be difficult and costly to measure. In the case of Syria, the study was based on estimated adoption rates in the PPB and CPB programs and weighted yield gains from the respective varieties. Using a gross economic benefit model, benefits were calculated for both PPB and CPB and compared with the estimated investment costs borne by the respective institutions for PPB and CPB. Under the baseline scenario, the benefit/cost ratio for PPB was 39 and the internal rate of return (IRR) was $46 \%$. In the case of CPB, the benefit/cost ratio was 15 , while the IRR was $19 \%$. Sensitivity analysis, assuming that only $50 \%$ of the adoption rate and $50 \%$ of the yield gain for the varieties produced by the two programs would be realized, resulted in the benefit/cost ratio and IRR remaining favorable at 10 and $33 \%$, respectively, for PPB.

The decentralization component of a PPB program is often considered to be the most expensive part. The 
most convincing evidence that decentralization per se is cost effective is given by the breeding programs in Australia, which remained decentralized even after privatization (Pederson and Rathjen, 1981; Cooper et al., 1997).

\section{CONCLUSIONS}

The objectives of this paper were to critically review the most common ways of measuring plant breeding efficiency and to redefine plant breeding efficiency in terms of response to selection, adoption, and cost effectiveness. The main conclusion of the paper is that increasing the response to selection, adoption, and the benefit/cost ratio is possible by combining decentralized selection and farmers' (or generally clients') participation in a PPB program. Selection theory shows that decentralization (i.e., direct selection in the target environment) is nearly always more efficient in terms of response to selection (Simmonds, 1991). The combination of decentralized selection and farmers' participation in a PPB program, briefly described in this paper and detailed elsewhere (Ceccarelli and Grando, 2007), increases the efficiency of a plant breeding program by increasing adoption and, hence, increasing the benefit/cost ratio.

The paper also showed that a PPB program has other advantages, one of which is the increase in agrobiodiversity with a rapid turnover of varieties both in space and time. Such a level of agrobiodiversity creates an almost insurmountable barrier to pests and diseases, and allows a rapid and continuous adaptation to climate changes. Given the importance of agrobiodiversity and the dangers associated with its decline (Cardinale et al., 2012; Hooper et al., 2012), and given that many measures of genetic diversity are available (Mohammadi and Prasanna, 2003), we conclude that a measure of agrobiodiversity between varieties adopted by farmers and generated by different breeding programs could be used as an additional measure of breeding efficiency. Therefore, PPB could reverse the tendency of modern plant breeding toward uniform varieties (Ceccarelli et al., 2013a), as if uniformity were the key to produce enough food. Therefore, PPB being one of the recommendations of the Special Rapporteur to the United Nations on the Right to Food is not surprising (De Schutter, 2014).

International breeding programs such as those of the CGIAR can easily be modified into PPB programs, which can be achieved by first decentralizing most of the selection work to national programs by gradually replacing the traditional international nurseries with targeted segregating populations, with the possible addition of specific genetic stocks. The distribution of segregating populations reduces the danger of useful lines being discarded because of their relatively poor performance at research stations (Ceccarelli et al., 1994). This will benefit from the extensive training programs on plant breeding conducted by CGIAR during the last $30 \mathrm{yr}$. An example of what CGIAR centers could do to contribute to agrobiodiversity is shown in Fig. 8.10 in Ceccarelli et al. (2013a), which reflects the decentralization of ICARDA's barley breeding program. It was started in 1991, with the distribution of targeted segregating populations first to Morocco, Algeria, Tunisia, and Libya (Ceccarelli et al., 1994) and later to Iraq in 1992, to Egypt in 1995, and gradually to other countries.

In that model, a CGIAR breeding program generates genetic variability by performing targeted crosses. These crosses are distributed through the various national programs to farmers' fields where PPB programs are implemented. The adopted varieties can be used directly by the national programs as parents in their crossing programs or handed over to the CGIAR breeding program for the same purpose, and a new cycle starts. During the process, material and information feedback is essential to making the entire process more precisely targeted. Because the adopted variety can be related to a specific number of targeted crosses, at least one of the efficiency measures can be easily calculated. A scheme such as the one shown in Fig. 8.10, if applied by all CGIAR centers to the main food crops in the poorest countries, would represent a major contribution to the increase of agricultural production, the enhancement of agrobiodiversity, and thus to adaptation to climate changes and to food security.

\section{Acknowledgments}

I thank E. Manyasa, M. Singh, and J. Dawson for valuable feedback on the manuscript and four anonymous reviewers who contributed considerably to improving the manuscript. The paper was written as part of the activities of the European Community's Seventh Framework 23 Program (FP7/2007-2013) under the grant agreement no. 245058 SOLIBAM (Strategies for Organic and Low-Input Integrated Breeding and Management).

\section{References}

Adesina, A.A., and J. Baidu-Forson. 1995. Farmers' perceptions and adoption of new agricultural technology: Evidence from analysis in Burkina Faso and Guinea, West Africa. Agric. Econ. 13:1-9. doi:10.1016/0169-5150(95)01142-8

Allard, R.W. 1960. Principles of plant breeding. John Wiley \& Sons, New York.

Allen, F.L., R.E. Comstock, and D.C. Rasmusson. 1978. Optimal environments for yield testing. Crop Sci. 18:747-751. doi:10.2135/ cropsci1978.0011183X001800050013x

Alpuerto, V.E., G.W. Norton, J. Alwang, and A.M. Ismail. 2009. Economic impact analysis of marker-assisted breeding for tolerance to salinity and phosphorous deficiency in rice. Rev. Agric. Econ. 31:779-792. doi:10.1111/j.1467-9353.2009.01466.x

Annicchiarico, P. 2002. Genotype $\times$ environment interactions. Challenges and opportunities for plant breeding and cultivar recommendations. FAO Plant Production and Protection Paper 174. FAO, Rome.

Annicchiarico, P. 2007. Wide- versus specific-adaptation strategy for lucerne breeding in northern Italy. Theor. Appl. Genet. 114:647657. doi:10.1007/s00122-006-0465-1

Annicchiarico, P., F. Bellah, and T. Chiari. 2005. Defining subregions and estimating benefits for a specific-adaptation strategy by breeding programs: A case study. Crop Sci. 45:1741-1749. doi:10.2135/ cropsci2004.0524 
Atlin, G.N., M. Cooper, and A. Bjørnstad. 2001. A comparison of formal and participatory breeding approaches using selection theory. Euphytica 122:463-475. doi:10.1023/A:1017557307800

Aw-Hassan, A., A. Mazid, and H. Salahieh. 2008. The role of informal farmer-to-farmer seed distribution in diffusion of new barley varieties in Syria. Exp. Agric. 44:413-431. doi:10.1017/ S001447970800642X

Bänziger, M., and M. Cooper. 2001. Breeding for low input conditions and consequences for participatory plant breeding: Examples from tropical maize and wheat. Euphytica 122:503-519. doi:10.1023/A:1017510928038

Belicka, I., and M. Bleidere. 2005. Variety testing for organic farming: Current status and problems in Europe. Seminar on environmental friendly food production system: Requirements for plant breeding and seed production. Envirfood, Talsi, Latvia. 12 p.

Bellon, M.R. 2006. Crop research to benefit poor farmers in marginal areas of the developing world: A review of technical challenges and tools. CAB Rev.: Persp. Agric. Vet. Sci. Nutr. Nat. Res. 1(070):1-11.

Bishaw, Z., and M. Turner. 2008. Linking participatory plant breeding to the seed supply system. Euphytica 163:31-44. doi:10.1007/ s10681-007-9572-6

Brush, S.B. 1995. In situ conservation of landraces in centers of crop diversity. Crop Sci. 35:346-354. doi:10.2135/cropsci1995.0011183 $\mathrm{X} 003500020009 \mathrm{x}$

Byerlee, D., and E.H. de Polanco. 1986. Farmers' stepwise adoption of technological packages: Evidence from the Mexican Altiplano. Am. J. Agric. Econ. 68:519-527. doi:10.2307/1241537

Calhoun, D.S., G. Gebeyehu, A. Miranda, S. Rajaram, and M. van Ginkel. 1994. Choosing evaluation environments to increase wheat grain yield under drought conditions. Crop Sci. 34:673678. doi:10.2135/cropsci1994.0011183X003400030014x

Cardinale, B.J., J.E. Duffy, A. Gonzalez, D.U. Hooper, C. Perrings, P. Venail, et al. 2012. Biodiversity loss and its impact on humanity. Nature 486:59-67. doi:10.1038/nature11148

Ceccarelli, S. 1994. Specific adaptation and breeding for marginal conditions. Euphytica 77:205-219. doi:10.1007/BF02262633

Ceccarelli, S. 1996. Adaptation to low/high input cultivation. Euphytica 92:203-214. doi:10.1007/BF00022846

Ceccarelli, S. 2009. Main stages of a plant breeding programme. In: S. Ceccarelli, E.P. Guimaraes, and E. Weltzien, editors, Plant breeding and farmer participation. FAO, Rome. p. 63-74.

Ceccarelli, S. 2012. Plant breeding with farmers-A technical manual. ICARDA, Aleppo, Syria.

Ceccarelli, S., and S. Grando. 2007. Decentralized-participatory plant breeding: An example of demand driven research. Euphytica 155:349-360. doi:10.1007/s10681-006-9336-8

Ceccarelli, S., E. Acevedo, and S. Grando. 1991. Breeding for yield stability in unpredictable environments: Single traits, interaction between traits, and architecture of genotypes. Euphytica 56:169185. doi:10.1007/BF00042061

Ceccarelli, S., W. Erskine, S. Grando, and J. Hamblin. 1994. Genotype $\times$ environment interaction and international breeding programmes. Exp. Agric. 30:177-187. doi:10.1017/S0014479700024121

Ceccarelli, S., A. Galie, and S. Grando. 2013a. Participatory breeding for climate change-related traits. In: C. Kole, editor, Genomics and breeding for climate-resilient crops. Vol. 1. Springer-Verlag, Berlin. p. 331-376.

Ceccarelli, S., A. Galié, Y. Mustafa, and S. Grando. 2012. Syria: Participatory barley breeding-Farmers' input becomes everyone's gain. In: M. Ruiz and R. Vernooy, editors, The custodians of biodiversity: Sharing access and benefits to genetic resources. Earthscan, 2 Park Square, Milton Park, Abingdon, Oxon OX14 4RN. p. 53-66.
Ceccarelli, S., and S. Grando. 2012. An example of participatory plant breeding: Barley at ICARDA. In: G. Acquaah, editor, Principles of plant genetics and breeding. Second ed. Wiley-Blackwell, Oxford. p. 501-504.

Ceccarelli, S., S. Grando, and F. Capettini. 2011. Barley breeding history, progress, objectives, and technology, Near East, North and East Africa and Latin America. In: S.E. Ullrich, editor, Barley: Production, improvement and uses. Wiley-Blackwell, Ames, Iowa. p. 210-220.

Ceccarelli, S., S. Grando, and T. Winge. 2013b. Participatory barley breeding in Syria. In: R. Andersen and T. Winge, editors, Realising farmers' rights to crop genetic resources: Success stories and best practices. Routledge, Abingdon. p. 97-116.

Ceccarelli, S., E.P. Guimaraes, and E. Weltzien, editors. 2009. Plant breeding and farmer participation. FAO, Rome. 671 p.

Cleveland, D.A., and D. Soleri. (eds.) 2002. Farmers, scientists and plant breeding. CABI Publishing, New York.

Cooper, M., R.E. Stucker, I.H. DeLacy, and B.D. Harch. 1997. Wheat breeding nurseries, target environments, and indirect selection for grain yield. Crop Sci. 37:1168-1176. doi:10.2135/cropsci1997.0011 183X003700040024x

Cullis, B.R., A.B. Smith, and N.E. Coombes. 2006. On the design of early generation variety trials with correlated data. J. Agric. Biol. Environ. Stat. 11:381-393. doi:10.1198/108571106X154443

De Schutter, O. 2014. Final report: The transformative potential of the right to food. Report of the special rapporteur on the right to food. Olivier De Schutter, United Nations General Assembly, A/ HRC/25/57, 28 p.

Eberhart, S.A. 1970. Factors affecting efficiencies of breeding methods. Afric. Soils 15:669-680.

Falconer, D.S. 1981. Introduction to quantitative genetics. 2nd ed. Longman Group Ltd., London.

Fehr, W.R. (ed.) 1984. Genetic contributions to yield gains of five major crop plants. CSSA Spec. Publ. 7. ASA and CSSA, Madison, WI.

Flower, D.J. 1996. Physiological and morphological features determining the performance of the sorghum landraces of northern Nigeria. Exp. Agric. 32:129-141. doi:10.1017/S0014479700026041

Gepts, P. 2002. A comparison between crop domestication, classical plant breeding, and genetic engineering. Crop Sci. 42:1780-1790. doi:10.2135/cropsci2002.1780

Gepts, P. 2006. Plant genetic resources conservation and utilization: The accomplishments and future of a societal insurance policy. Crop Sci. 46:2278-2292. doi:10.2135/cropsci2006.03.0169gas

Gepts, P., and J. Hancock. 2006. The future of plant breeding. Crop Sci. 46:1630-1634. doi:10.2135/cropsci2005-12-0497op

Goulden, C.H. 1939. Problems in plant selection. In: Proceedings of the Seventh International Genetics Congress. Cambridge Univ. Press. p. 132-133.

Hooper, D.U., E.C. Adair, B.J. Cardinale, J.E.K. Byrnes, B.A. Hungate, K.L. Matulich, et al. 2012. A global synthesis reveals biodiversity loss as a major driver of ecosystem change. Nature 486:105-108.

Hossain, M., W.M.H. Jaim, T.R. Paris, and B. Hardy. (eds.) 2012. Adoption and diffusion of modern rice varieties in Bangladesh and eastern India. International Rice Research Institute, Los Baños, Philippines.

ICARDA. 2007. ICARDA annual report 2006. International Center for Agricultural Research in the Dry Areas, Aleppo, Syria. 153 p.

ICRISAT. 2012. The jewels of ICRISAT. Patancheru 502 324, Andhra Pradesh, India: International Crops Research Institute for the Semi-Arid Tropics (ICRISAT). 68 p.

Jalleta, T. 2004. Participatory evaluation of the performance of some improved bread wheat (Triticum aestivum) varieties in the Jijiga Plains of eastern Ethiopia. Exp. Agric. 40:89-97. doi:10.1017/ S0014479703001479 
Jansen, H.G.P., T.S. Walker, and R. Barker. 1990. Adoption ceilings and modern coarse cereal cultivars in India. Am. J. Agric. Econ. 72:653-663. doi:10.2307/1243035

Jones, K., L.L. Glenna, and E. Weltzien. 2014. Assessing participatory processes and outcomes in agricultural research for development from participants' perspectives. J. Rural Stud. 35:91-100. doi:10.1016/j.jrurstud.2014.04.010

Kelley, T.G., P. Parthasarathy Rao, E. Weltzien, and M.L. Purohit. 1996. Adoption of improved cultivars of pearl millet in an arid environment: Straw yield and quality considerations in western Rajasthan. Exp. Agric. 32:161-171. doi:10.1017/S0014479700026077

Kempton, R.A., and A.C. Gleeson. 1997. Unreplicated trials. In: R.A. Kempton and P.N. Fox, editors, Statistical methods for plant variety evaluation. Chapman and Hall, London. p. 86-100.

Legg, J.P., and J.M. Thresh. 2000. Cassava mosaic virus disease in East Africa: A dynamic disease in a changing environment. Virus Res. 71:135-149. doi:10.1016/S0168-1702(00)00194-5

Li, J., E.T. Lammerts van Bueren, J. Jiggins, and C. Leeuwis. 2012. Farmers' adoption of maize (Zea mays L.) hybrids and the persistence of landraces in Southwest China: Implications for policy and breeding. Genet. Resour. Crop Evol. 59:1147-1160. doi:10.1007/ s10722-011-9750-1

Mangione, D., S. Senni, M. Puccioni, S. Grando, and S. Ceccarelli. 2006. The cost of participatory barley breeding. Euphytica 150:289-306. doi:10.1007/s10681-006-0226-x

Maredia, M.K., and D.A. Raitzer. 2010. Estimating overall returns to international agricultural research in Africa through benefit-cost analysis: A "best-evidence" approach. Agric. Econ. 41:81-100. doi:10.1111/j.1574-0862.2009.00427.x

Mohammadi, S.A., and B.M. Prasanna. 2003. Analysis of genetic diversity in crop plants-Salient statistical tools and considerations. Crop Sci. 43:1235-1248. doi:10.2135/cropsci2003.1235

Morris, M.A., and P.W. Heisey. 2003. Estimating the benefits of plant breeding research: Methodological issues and practical challenges. Agric. Econ. 29:241-252. doi:10.1111/j.1574-0862.2003.tb00161.x

Morris, M.L., J.H. Dubin, and T. Pokhrel. 1992. Returns to wheat research in Nepal. CIMMYT Economics Working Paper 92-04. International Maize and Wheat Improvement Centre (CIMMYT), Mexico.

Pederson, D.G., and A.J. Rathjen. 1981. Choosing trial sites to maximize selection response for grain yield in spring wheat. Aust. J. Agric. Res. 32:411-424. doi:10.1071/AR9810411

Reguieg, M.M., M. Labdi, A. Benbelkacem, M. Hamou, M.E.H. Maatougui, S. Grando, and S. Ceccarelli. 2013. First experience on participatory barley breeding in Algeria. J. Crop Improv. 27:118. doi:10.1080/15427528.2013.794756

Ribaut, J.M., and D. Hoisington. 1998. Marker-assisted selection: New tools and strategies. Trends Plant Sci. 3:236-239. doi:10.1016/ S1360-1385(98)01240-0

Ribaut, J.M., M.C. de Vicente, and X. Delannay. 2010. Molecular breeding in developing countries: Challenges and perspectives. Curr. Opin. Plant Biol. 13:213-218. doi:10.1016/j.pbi.2009.12.011

Saade, M., F. Nassif, A. Amri, and H. El Baghati. 1993. Constraints to the adoption of barley varieties in Morocco. Expert Report. ICARDA, Aleppo, Syria.

Sall, S., D. Norman, and A.M. Featherstone. 2000. Quantitative assessment of improved rice variety adoption: The farmer's perspective. Agric. Syst. 66:129-144. doi:10.1016/S0308-521X(00)00040-8

Schnell, F.W. 1982. A synoptic study of the methods and categories of plant breeding. Z. Pflanzenzuech. 89:1-18.

Simmonds, N.W. 1991. Selection for local adaptation in a plant breeding programme. Theor. Appl. Genet. 82:363-367. doi:10.1007/ BF02190624
Simmonds, N.W., and J. Smartt. 1999. Principles of crop improvement. 2nd ed. Wiley-Blackwell, Mead, Oxford, UK.

Singh, M., R.S. Malhotra, S. Ceccarelli, A. Sarker, S. Grando, and W. Erskine. 2003. Spatial variability models to improve dryland field trials. Exp. Agric. 39:151-160. doi:10.1017/S0014479702001175

Smale, M., M.R. Bellon, J.A. Aguirre, I. Manuel Rosas, J. Mendoza, A.M. Solano, R. Martínez, A. Ramírez, and J. Berthaud. 2003. The economic costs and benefits of a participatory project to conserve maize landraces on farms in Oaxaca, Mexico. Agric. Econ. 29:265-275. doi:10.1111/j.1574-0862.2003.tb00163.x

Sthapit, B.R., K.D. Joshi, and J.R. Witcombe. 1996. Farmer participatory crop improvement. III. Participatory plant breeding, a case study for rice in Nepal. Exp. Agric. 32:479-496. doi:10.1017/ S001447970000154X

Thomas, P. 1987. Cultivar testing: A seed industry perspective. HortScience 22:1212-1214.

Tripp, R., N. Lowaars, W.J. Van der Burg, D.S. Virk, and J.R. Witcombe. 1997. Alternatives for seed regulatory reform. An analysis of variety testing, variety regulation and seed quality control. Agricultural Administration (Research and Extension), London. Overseas Development Institute Network Paper No. 69:1-25.

Wallace, D.H., J.P. Baudoin, J. Beaver, D.P. Coyne, D.E. Halseth, P.N. Masaya, et al. 1993. Improving efficiency of breeding for higher crop yield. Theor. Appl. Genet. 86:27-40.

Weltzien, E., and A. Christinck. 2009. Methodologies for priority setting. In: S. Ceccarelli, E.P. Guimaraes, and E. Weltzien, editors, Plant breeding and farmer participation. FAO, Rome. p. 75-105.

Weltzien, E., and J.R. Witcombe. 1989. Pearl millet improvement for the Thar Desert, Rajasthan, India. Proceedings of the XII Eucarpia Congress, Science for Plant Breeding, Book of Poster Abstracts. 23-26.

Wien, H.C. 1987. Vegetable cultivar testing: Introduction to the symposium. HortScience 22:1210.

Windhausen, V.S., S. Wagener, C. Magorokosho, D. Makumbi, B. Vivek, H.-P. Piepho, et al. 2012. Strategies to subdivide a target population of environments: Results from the CIMMYT-led maize hybrid testing programs in Africa. Crop Sci. 52:2143-2152. doi:10.2135/cropsci2012.02.0125

Witcombe, J.R., A. Joshi, K.D. Joshi, and B.R. Sthapit. 1996. Farmer participatory crop improvement. I. Varietal selection and breeding methods and their impact on biodiversity. Exp. Agric. 32:445460. doi:10.1017/S0014479700001526

Witcombe, J.R., A.J. Packwood, A.G.B. Raj, and D.S. Virk. 1998. The extent and rate of adoption of modern cultivars in India. In: J.R. Witcombe, D.S. Virk, and J. Farrington, editors, Seeds of choice: Making the most of new varieties for small farmers. Oxford and IBH Publishing Co., New Delhi, and Intermediate Technology Group, London. p. 53-68.

Witcombe, J.R., S. Gyawali, M. Subedi, D.S. Virk, and K.D. Joshi. 2013. Plant breeding can be made more efficient by having fewer, better crosses. BMC Plant Biol. 13:22. doi:10.1186/1471-2229-13-22

Wolfe, M.S., J.P. Baresel, D. Desclaux, I. Goldringer, S. Hoad, G. Kovacs, F. Löschenberger, T. Miedaner, H. Østergård, and E.T. Lammerts van Bueren. 2008. Developments in breeding cereals for organic agriculture. Euphytica 163:323-346. doi:10.1007/ s10681-008-9690-9

Yahiaoui, S., A. Cuesta-Marcos, M.P. Gracia, B. Medina, J. Lasa, A. Casas, et al. 2014. Spanish barley landraces outperform modern cultivars at low-productivity sites. Plant Breed. 10.1111/pbr.12148.

Yan, W., M.S. Kang, B.L. Ma, S. Woods, and P.L. Cornelius. 2007. GGEbiplot vs. AMMI analysis of genotype-by-environment data. Crop Sci. 47:643-655. doi:10.2135/cropsci2006.06.0374 